\title{
Preoperative assessment in non-cardiac surgery: a stepwise approach
}

\author{
María Cristina Moreno-Del Castillo, ${ }^{1}$ Jorge Valladares-García, ${ }^{1}$ Javier José Hernández-Buen Abad ${ }^{2}$ and \\ José Halabe-Cherem ${ }^{3 *}$ \\ ${ }^{1}$ Centro Médico ABC, Department of Internal Medicine; ${ }^{2}$ Centro Médico ABC, Department of Preventive Medicine; ${ }^{3}$ Universidad Nacional Autónoma \\ de Mexico, Faculty of Medicine, Division of Graduate Studies. Ciudad de México, Mexico
}

\begin{abstract}
Preoperative assessment in non-cardiac surgery is essential to reducing the rate of in-hospital complications. Its purpose is to identify patients with higher levels of risk. Preoperative assessment should not be restricted to cardiovascular aspects, but it should focus on all organs and systems and include medication reconciliation. The purpose of this article is to approach the performance of a preoperative assessment in non-cardiac surgery from the perspective of the internist, with the purpose to $h$ elp prevent adverse events and improve the overall outcome.
\end{abstract}

KEY WORDS: Preoperative assessment. Surgical risk. Cardiovascular risk. Non-cardiac surgery. Internal medicine

\section{Introduction}

Assessment of the patient that will undergo a surgical procedure is a complex art that is part of the internist's responsibilities, but the outcome is "[..] the result of a collaborative effort between different areas of hospital medicine".

Preoperative assessment should not be restricted to the prevention of cardiovascular events, given that there are multiple pathologies that could turn into difficulties during the perioperative period..$^{2-4}$ Emergency surgery should not be delayed by an assessment, but the internist doctor should be alert to manage the patient during the perioperative period.

The purpose of this review is to review, step-bystep, preoperative assessment in non-cardiac surgery from the perspective of the internist doctor, in order to help prevent adverse events and improve general outcome (Table 1).

\section{Patient history}

A general patient history should be made emphasizing on functional assessment, fasting time (in hospitalized patients), medical history and complete list of medications with their respective dosage, surgical history and related complications and allergic reactions, as well as an extensive questionnaire by organs and systems in search for cardiovascular and pulmonary risk factors, and information enough to calculate risk scales. In addition, every woman of childbearing age should be asked if she is pregnant or if there is the possibility of being pregnant. ${ }^{5}$

\section{Functional assessment}

Functional assessment has been associated with perioperative mortality. ${ }^{6}$ The Metabolic Equivalent of Task (MET) or metabolic activity equivalent estimate
Gac Med Mex. 2019;155:275-282

Contents available at PubMed www.gacetamedicademexico.com 
Table 1. Preoperative assessment in non-cardiac surgery

\section{Steps}

1. Surgical diagnosis.

2. Scheduled operation.

3. Scheduled anesthesia.

4. Surgical risk classification.

5. Recommendations.

\section{Breakdown}

1. General patient history aimed at obtaining the necessary information to perform all cardiac, pulmonary, thrombotic and infectious risk calculations. Request laboratory and imaging focused tests.

2. Apply risk scales and record the following results in the analysis:

a) Risk according to the type of surgery.

b) Cardiovascular: performance status, ASA, Gupta, Lee.

c) Pulmonary: ARISCAT/Canet, Gupta for respiratory failure, Gupta for pneumonia and STOP - BANG screening.

d) Thrombotic: Caprini IMPROVE.

3. Recommendations

a) Presurgical recommendations: smoking, alcoholism, drug addiction and medication discontinuation. Fasting time. Dose, dosage and timing of antibiotic prophylaxis administration for surgical wound infection. Need for additional presurgical test based on risk and interrogation (e.g., echocardiography, respiratory function tests).

b) Post-surgical recommendations: need for critical care area for postoperative surveillance with monitoring according to cardiovascular or pulmonary risk. Pulmonary rehabilitation or need for positive pressure during the postoperative period based on risk. Thromboprophylaxis according to risk. Medications to be avoided according to patient characteristics and risk of complications.

c) Drug reconciliation: establish which medications the patient should discontinue and when, which ones should be continued, when should they be restarted and, if necessary, start any other.

can be used. ${ }^{7}$ METs can be accurately calculated by means of a treadmill stress test, but for the purposes of preoperative assessment, the following question should be asked: can the patient climb one floor of stairs or walk two blocks without fatigue? If the answer is affirmative, the patient has more than $4 \mathrm{MET}$, and if it is negative, he/she has less. The above determines the need for complementary cardiovascular tests.

\section{Alcohol consumption and fasting}

The AUDIT-c screening scale for alcohol consumption over the previous year can be used; a result $\leq 9$ is associated with increased hospital stay, higher infection rate and longer stay in intensive care..$^{8}$ In addition, patients with significant alcohol consumption may present withdrawal syndrome during surgery; ${ }^{9}$ if this is the case, the patient can be monitorized with the CIWA-Ar questionnaire (Clinical Institute Withdrawal Assessment Scale for Alcohol, revised) and have prophylaxis administered according to the results. ${ }^{10}$

Fasting time is important to reduce the risk of broncho-aspiration. Currently, a minimum two-hour fasting for clear fluids (including coffee without milk), six hours for a light meal (including milk) and eight hours for a copious meal is recommended. The use of prokinetics or gastric acid suppressors is not routinely recommended. Ultrasonographic measurement of gastric content before anesthesia induction, particularly in patients who have not followed the fasting directions, might be useful, but it is not a standardized practice. $^{11}$

\section{Pulmonary assessment and smoking}

A high smoking index (which can be by indirect smoking) is associated with chronic obstructive pulmonary disease (COPD), blood viscosity, decreased healing and surgical site infection. ${ }^{12}$ Cigarrette smoking discontinuation at least four weeks prior decreases respiratory, infectious and healing complications; discontinuation two weeks prior decreases respiratory complications. ${ }^{13}$ Nicotine supplements may be used as an aid in tobacco withdrawal. ${ }^{14}$

Pulmonary complications may be due to patient factors (COPD, smoking, age, pulmonary hypertension, obstructive sleep apnea-hypopnea syndrome [OSAHS]) or type of surgery and general anesthesia. 
Table 2. Comparison of variables used by the different cardiovascular risk scales

\begin{tabular}{|c|c|c|c|}
\hline Variable & Gupta^ & $\operatorname{Lee}^{\&}$ & Goldman ${ }^{\&}$ \\
\hline Age & Yes & No & Yes \\
\hline Emergency surgery & No & No & Yes \\
\hline Type of procedure (high risk) & Yes & Yes & Yes \\
\hline Coronary artery disease & No & Yes & Yes (AMI) \\
\hline Significant aortic stenosis & No & No & Yes \\
\hline Arrhythmias & No & No & Yes \\
\hline Congestive heart failure & No & Yes & Yes (S3 or jugular engorgement) \\
\hline Insulin-managed diabetes mellitus & No & Yes & No \\
\hline Creatinine (mg/dL) & $\geq 15$ & $>2$ & $\geq 3$ \\
\hline History of CVD & No & Yes & No \\
\hline ASA Classification & Yes & No & No \\
\hline Preoperative performance status & Yes & No & Poor general status* \\
\hline \multicolumn{4}{|c|}{ 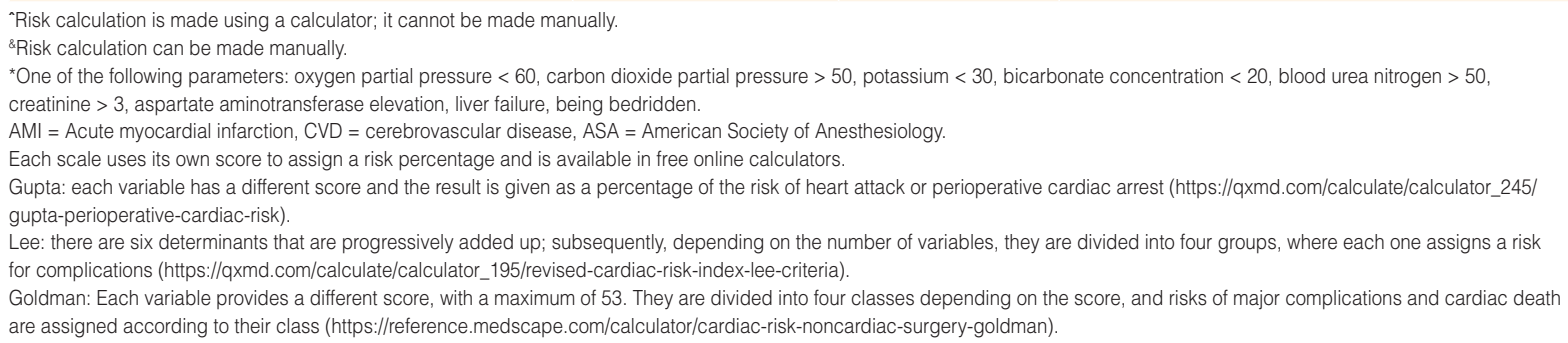 } \\
\hline
\end{tabular}

Paraclinical tests that are associated with pulmonary morbidity are albumin $<3.5 \mathrm{mg} / \mathrm{dL}$, low hemoglobin and blood urea nitrogen $\geq 30 \mathrm{mg} / \mathrm{dL}^{2}$ The following four scales are useful for assessing pulmonary risk:

- Assess Respiratory Risk in Surgical patients in Catalonia (ARISCAT) scale. ${ }^{3}$

- Gupta scales for pulmonary complications. ${ }^{4,15}$

- OSAHS screening scale, STOP BANG (Snoring Tired Observed Apnea, Blood Pressure, BMI, Age, Neck Circumference). ${ }^{16}$

The ARISCAT or Canet scale predicts postoperative pulmonary complications (infections requiring antibiotic use, respiratory failure, pleural effusion, atelectasis, pneumothorax, bronchospasm or aspiration pneumonitis). ${ }^{3}$

There are two Gupta scales for pulmonary complications, the first one serves to predict respiratory failure ${ }^{15}$ and the second to predict pneumonia within the first 30 postoperative days. ${ }^{4}$ They can be freely downloaded (http://www.surgical-riskcalculator.com).

During preoperative assessment, COPD and asthma treatment should be optimized. If there are high risks, the surgical indication should be reconsidered. ${ }^{2}$ Standardized protocols that have shown risk pulmonary reduction (ERAS or ERAS $+{ }^{17}$ which adds to the ICOUGH protocol ${ }^{18}$ ) and that include decreasing the use of intravenous opioids, intravenous fluid management, pulmonary physiotherapy with incentive inspirometer, oral hygiene, early postoperative ambulation and headboard elevation, can also be applied. ${ }^{17,18}$

OSAHS is associated with respiratory failure and perioperative cardiovascular mortality. STOP BANG, a simple screening scale, can be used..$^{19}$ A STOP BANG score $\geq 3$ is considered risk for experiencing moderate to severe OSAHS. ${ }^{19}$ If the resource is available, outpatients should undergo a polysomnography study in order to confirm or rule out the diagnosis and establish appropriate treatment. If the patient is not able to use airway continuous positive pressure in the post-surgical period or has cardiovascular comorbidities, he/she will benefit from postoperative surveillance in the intermediate or intensive care unit, even if the planned procedure was in the outpatient setting. ${ }^{20}$ In ambulatory surgery patients with suspected OSAHS in whom parenteral opioids are being used or in those with recurrent respiratory events in the recovery room, monitoring with continuous oximetry is recommended and even positive pressure therapy in 


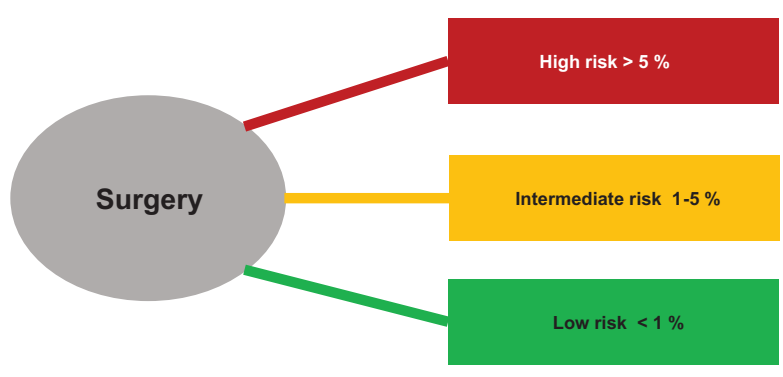

Figure 1. Examples of surgical risk according to the type of surgery. High risk = major aortic and vascular, pancreatic-duodenal, biliary or hepatic duct, and adrenal surgery, esophagectomy, pneumectomy, intestinal perforation repair. Intermediate risk = splenectomy, cholecystectomy, symptomatic carotid surgery, peripheral artery angioplasty, endovascular aneurysm, head and neck, kidney transplant, urological and major gynecological surgery. Low risk = breast, dental, thyroid, eye, reconstructive, asymptomatic carotid, minor gynecological, minor orthopedic, and transurethral prostate surgery. Adapted from Glance et al. ${ }^{31}$

monitored units. ${ }^{21}$ In OSAHS, caution should be exercised with the use of medications that induce respiratory depression (benzodiazepines and opiates), since they can cause respiratory arrest in a patient of difficult orotracheal intubation.

\section{Cardiovascular risk scales and risk according to the type of surgery}

Cardiovascular assessment relies on scales that predict the likelihood of complications during the perioperative period. The first one was created by The American Society of Anesthesiologists (ASA) in 1941, ${ }^{22}$ followed by those created by Goldman in $1977,{ }^{23}$ by Detsky in $1986,{ }^{24}$ by Lee in $1999^{25}$ and Gupta in $2011 .{ }^{26}$

The ASA scale is highly useful, but its use is recommended in combination with others, ${ }^{22}$ since it involves subjective judgment. It has the advantage of being simple and reaching a sufficient degree of generalization so that it can be used as an almost universal communication language.

The Goldman index serves to rule out coronary artery disease, not so much to detect it (negative predictive value of $96.8 \%$, positive predictive value $21.6 \%) .{ }^{27}$ Its use in combination with the ASA scale increases its diagnostic certainty. ${ }^{28}$

Lee's index or "revised cardiac risk" has better sensitivity and specificity for cardiovascular morbidity.

Gupta et al. validated a scale of risk for cardiovascular complications within the first 30 postoperative days in 200 hospitals and 200,000 patients..$^{30}$ The advantages of this scale lie in that it considered most recent population and new surgical techniques; it has demonstrated superiority to predict unwanted events in comparison with previous scales ${ }^{30}$ (Table 2).
The type of surgery per se is related to a different probability of cardiovascular events such as myocardial infarction or death ${ }^{31}$ (Figure 1).

Based on the results of cardiac surgery risk scales, the type of surgery and patient functional assessment, the required complementary studies can be decided (electrocardiogram, resting echocardiogram or stress tests with or without drugs -treadmill, ergometer, dobutamine stress TTE, nuclear medicine, magnetic resonance imaging- $)^{7,32}$ (Table 3). When a patient has a negative stress test for myocardial ischemia, or when ischemia is mild to moderate, the patient can undergo surgery; if it is extensive, the surgical indication should be reassessed, and the usefulness of myocardial revascularization evaluated, considering that after the procedure the patient will require antiplatelet agents for a long period, which in turn affects the performance of the surgical procedure. ${ }^{29}$ Routine cardiac catheterization as a screening method is uncertain in patients with low performance status and cardiovascular risk factors (Lee $\geq 2, M E T<4$ ) and who will undergo intermediate or high-risk surgery or vascular surgery. In these cases it would be preferable starting with non-invasive methods such as myocardial stress tests. ${ }^{33}$

\section{Risk of thrombosis and bleeding}

Bleeding risk can be assessed using the IMPROVE scale (https://www.outcomes-umassmed.org/improve/ risk_score/bleeding/index.html). Thrombotic complications can be preventable if they are identified on time. The main isolated risk factor for a thromboembolic event is high-risk surgery, cancer surgery and hip or knee joint replacements. ${ }^{34}$ The risk of thrombosis is classified with the Caprini scale (https://venousdisease. com/dvt-risk-assessment-online/), in which regard the following recommendations are issued: ${ }^{34}$

- Very low (< $0.5 \%)$ : early ambulation.

- Low (1.5\%): gradu ted compression stockings or pharmacological prophylaxis during hospitalization.

- Moderate (3\%): pharmacological and mechanical prophylaxis during hospitalization

- High (6\%): pharmacological and mechanical prophylaxis for seven to 10 days (e.g., knee replacement surgery).

- Very high risk (6-18\%): pharmacological and mechanical prophylaxis for 30 days (e.g., hip replacement surgery).

The best option for mechanical prophylaxis is intermittent pneumatic compression. ${ }^{35}$ Pharmacological prophylaxis typically consists of subcutaneous 
Table 3. Indications for pre-surgical laboratory and imaging tests according to surgical risk

\begin{tabular}{|c|c|c|}
\hline Diagnostic test & Procedure factors & Patient factors \\
\hline Chest X-ray & $\begin{array}{l}\text { Intermediate to high risk (in addition to } \\
\text { patient factors) }\end{array}$ & $\begin{array}{l}\text { ASA } \geq 3 \text {, clinical suspicion of thoracic pathology, history of lung disease, } \\
\text { dyspnea of undetermined origin }\end{array}$ \\
\hline Electrocardiogram & $\begin{array}{l}\text { Intermediate-high risk surgery (higher } \\
\text { value if there is any patient factor, but it } \\
\text { can be performed if there are no } \\
\text { symptoms) }\end{array}$ & $\begin{array}{l}\text { Lee index } \geq 1 \text {. Clinical suspicion of heart disease or arrhythmia, } \\
\text { assessment of dyspnea of indeterminate origin. }\end{array}$ \\
\hline TTE & $\begin{array}{l}\text { Intermediate or high-risk surgery (with } \\
\text { risk factors and low functional capacity) }\end{array}$ & $\begin{array}{l}\text { Patients with MET }<4 \text { and Lee } \geq 1 \text { who will undergo high risk surgery, } \\
\text { with heart failure that has clinically worsened or in whom the test has } \\
\text { not been performed within the previous year; patients with myocardial } \\
\text { structural damage with suspected progression, evaluation of dyspnea of } \\
\text { undetermined origin. }\end{array}$ \\
\hline $\begin{array}{l}\text { Myocardial stress } \\
\text { studies }\end{array}$ & $\begin{array}{l}\text { Intermediate to high risk surgery (with } \\
\text { risk factors) }\end{array}$ & $\begin{array}{l}\text { Patients with Lee index } \geq 2 \text { and } \mathrm{MET}<4 \text { and who will undergo } \\
\text { intermediate to high risk surgery, particularly with Lee } \geq 3 \text { and in high-risk } \\
\text { surgery }\end{array}$ \\
\hline Troponin & $\begin{array}{l}\text { Intermediate to high risk } \\
\text { surgery (together with patient factors) }\end{array}$ & $\begin{array}{l}\text { Can be useful in patients with MET } \leq 4 \text { or Lee index }>1 \text { for vascular } \\
\text { surgery or }>2 \text { for nonvascular surgery }\end{array}$ \\
\hline Blood count & $\begin{array}{l}\text { Intermediate risk surgery } \\
\text { High risk surgery }\end{array}$ & $\begin{array}{l}\text { Patients with cardiovascular or renal disease. } \\
\text { All }\end{array}$ \\
\hline Kidney function tests & $\begin{array}{l}\text { Intermediate risk surgery } \\
\text { High risk surgery }\end{array}$ & $\begin{array}{l}\text { ASA } 3 \text { or } 4 \text { patients and ASA } 2 \text { patients with risk of acute kidney failure. } \\
\text { All }\end{array}$ \\
\hline Coagulation tests & $\begin{array}{l}\text { Intermediate risk surgery } \\
\text { High risk surgery }\end{array}$ & $\begin{array}{l}\text { Anticoagulated or liver disease patients } \\
\text { All }\end{array}$ \\
\hline Serum electrolytes & $\begin{array}{l}\text { Low risk surgery } \\
\text { Intermediate or high-risk surgery }\end{array}$ & $\begin{array}{l}\text { No } \\
\text { Patients with kidney failure or chronic use of medications that modify } \\
\text { serum electrolytes (diuretics, angiotensin converting enzyme inhibitors/ } \\
\text { angiotensin II receptor blockers). }\end{array}$ \\
\hline Urinalysis & Urological surgery with instrumentation & $\begin{array}{l}\text { If there are symptoms of infection request with urine culture and if } \\
\text { screening will change the management. }\end{array}$ \\
\hline Pregnancy test & Any & Offer to women of childbearing age with likelihood of pregnancy \\
\hline
\end{tabular}

administration of $40 \mathrm{mg}$ of low molecular weight heparin every 24 hours, which should be adjusted in certain cases, such as with a glomerular filtration rate $<30 \mathrm{~mL} /$ minute $^{36}$ or $\mathrm{BMl} \geq 40 \mathrm{~kg} / \mathrm{m}^{2}$. It should be discontinued at least 12 hours prior to the surgical procedure and be restarted at 24 hours, weighing the risk of bleeding with that of thrombosis. ${ }^{37}$ It is possible that the new direct-acting oral anticoagulants increase the risk of postoperative bleeding. ${ }^{38}$

\section{Laboratory and imaging studies}

Indiscriminate use of laboratory tests in preoperative assessment it is a common habit that does not favor the prognosis., ${ }^{1,39-41}$ In "healthy" patients in whom a low risk surgery will be performed (e.g., cataract surgery), skipping laboratory and imaging studies is suggested, and in intermediate to high-risk surgeries it will depend on their characteristics (Table 3). ${ }^{41,42}$

\section{Medication reconciliation}

\section{Beta-blockers and drugs for heart rate control (digoxin, amiodarone, ivabradine)}

They should be continued during the perioperative period. ${ }^{7,29}$ Not using beta-blockers in patients who are not taking them is suggested, since they can increase morbidity and mortality $43-45$

\section{ACEI/ARA 2}

If angiotensin converting enzyme inhibitors (ACEI) or angiotensin-2 receptor antagonists (ARA 2) were 
indicated in the patient for systemic arterial hypertension, discontinuing them one day prior to surgery is recommended, since they may cause amine-refractory perioperative hypotension; they should be restarted in the postoperative period according to the clinical evolution. If they are indicated as treatment for heart failure, continuing them can be considered, always weighing the risks. ${ }^{29,46}$

\section{Diuretics}

In case of hypertension, not taking the dose the day of surgery is recommended. They can be continued for the treatment of congestive heart failure, assessing the benefit of preventing fluid overload versus the risk of hypotension, kidney failure and electrolyte imbalance (hypokalemia, hypomagnesemia), which, in turn, might precipitate cardiac arrhythmias. Preoperative electrolytes should be requested. ${ }^{29}$

\section{Calcium antagonists}

Continuing them with caution in the perioperative period is recommended ${ }^{47}$ Nifedipine has been associated with increased mortality in aorto-abdominal surgery. ${ }^{29}$

\section{Statins}

Continuing them with no interruption in case of chronic use is recommended, ${ }^{7,29}$ and start them two weeks prior to vascular surgery; their use has been observed to decrease mortality. ${ }^{29}$

\section{Insulin}

In the hospitalized diabetic patient, the goal should be to maintain preprandial blood glucose $<140 \mathrm{mg} / \mathrm{dL}$ and casual blood glucose between 140 and $180 \mathrm{mg} / \mathrm{dL} .{ }^{48,49}$

- Insulin pump: continue basal infusion.

- Ultra-fast insulin: discontinue dose of the day of surgery.

- Premixed insulins: discontinue prior to surgery, change for intermediate-acting insulin.

- Intermediate-acting insulin: give $75 \%$ of the evening dose one day before surgery and 50 to $75 \%$ of the dose on the morning of surgery.

- Long-acting insulin: give $100 \%$ of the evening dose one day before surgery, 75 to $100 \%$ of the morning dose on the day of surgery.

\section{Metformin}

Discontinue 24 hours before (or 48 hours before if the patient is to receive intravenous contrast) in order to decrease the risk of lactic acidosis; restart 48 hours after surgery if there is no kidney failure, nausea or vomiting. Maintain glycemic control, with insulin if necessary. ${ }^{49}$

\section{Dipeptidyl petidase 4 (DPP-4) inhibitors, glucagon-like peptide-1 (GLP-1) receptor agonists, thiazolidinediones, sulfonylureas, meglitinides}

Discontinue one day before (verify half-life to decrease the risk of hypoglycemia) and restart one or two days before discharge in stable patients. If necessary, use insulin for glycemic control. ${ }^{48,49}$

\section{Corticosteroids}

In patients with suspected adrenal insufficiency or in those in whom corticosteroids have been applied during the previous year, perioperative stress doses (200 to $300 \mathrm{mg}$ of hydrocortisone in 24 hours) should be administered. ${ }^{50,51}$

\section{Nonsteroidal anti-inflammatory drugs}

Discontinue five to 10 days prior to the surgical procedure and restart upon achieving adequate hemostasis. ${ }^{52}$

\section{Low-dose aspirin}

In primary prevention, discontinuing seven to 10 days prior to surgery is suggested. ${ }^{53}$

\section{Dual antiplatelet therapy}

In recent stent placement, postponing elective surgery until safety ranges are met is recommended in order to prevent rethrombosis. If the stent is made of pure metal, waiting four to six weeks is recommended, and if it is drug-releasing, at least six months (if surgery is necessary with dual anti-aggregation, wait three months, but continue aspirin during the perioperative period) ${ }^{53}$ Restarting antiaggregants once hemostasis is achieved, at approximately 24 hours, is recommended. ${ }^{37.52}$ 


\section{Anticoagulants}

- Warfarin: its perioperative use depends on patient bleeding and thrombotic risk. At high risk of bleeding, discontinue five days before the surgical event and, if necessary, it can be reverted 24 to 48 hours before by using vitamin $\mathrm{K}$ and fresh frozen plasma. ${ }^{37,52}$ It can be restarted on the afternoon of the day of surgery because its effect takes several days. ${ }^{37}$ Heparin bridging therapy should be adjusted according to patient thrombotic risk. ${ }^{54}$

- Heparins: interrupt unfractionated intravenous heparin between two and six hours before the procedures and subcutaneous administration between 12 and 24 hours prior. In patients receiving low molecular weight heparin, interrupt it 24 hours prior to surgery. In patients with bypass, restarting them when hemostasis is achieved is recommended (approximately 48 hours after high-risk procedures) and discontinuing once warfarin reaches therapeutic levels. ${ }^{37}$

- Direct-acting anticoagulants: the decision of when to discontinue the treatment depends on several factors (two to three days on average, but glomerular filtration rate should be taken into account). Given that they exert their action relatively fast, restarting them 48 hours after high-risk surgical procedures is recommended. ${ }^{37}$

\section{Antimicrobial therapy for surgical wound- associated infection prophylaxis}

A single standard dose of antibiotic is suggested for the prophylaxis of surgical wound infection. The suggested administration timing is 60 minutes prior to the surgical incision; however, the half-life and administration route of some drugs should be taken into account. ${ }^{55,56}$ First and second-generation cephalosporins are the most widely used antibiotics, since they have a broad spectrum (gram-positive, gram-negative and anaerobic) and a good skin-level coverage. Cefazolin is the most widely used antibiotic (in Mexico, a good option is cephalothin). ${ }^{55}$ Alternatives to cephalosporins, especially in allergic patients, include vancomycin, clindamycin and fluoroquinolones (levofloxacin/ciprofloxacin). To ensure adequate concentration, repeating the initial dose is suggested if the procedure lasts more than two half-lives of the antibiotic, in patients with extensive burns or with blood loss greater than $1500 \mathrm{~mL} .{ }^{55}$ The dosing interval should be measured since the administration of the first dose and not since the beginning of the procedure. Administering a new dose in patients with chronic kidney disease is not suggested. For clean and clean-contaminated wounds, administering another dose after wound surgical closure is not suggested, even if drains have been placed. ${ }^{55,56}$ Repeating another dose after surgical wound closure is not suggested, since there is no difference in the outcome and, in addition, it is related to infection by Clostridium difficile. If prophylaxis is required after surgical time, it should have a duration of less than 24 hours. ${ }^{56}$

\section{Conclusions}

Preoperative assessment should not be restricted to cardiovascular risk assessment. Imaging and laboratory studies should be focused. The reduction of surgical complications is the result of a multidisciplinary hospital work where the internist plays a fundamental role by issuing recommendations in accordance with evidence-based medicine. There is great need to implement standardized hospital protocols to assess the population. This review is a summary of recommendations based on our interpretation of the literature and our experience and by no means should it replace clinical criteria.

\section{References}

1. Halabe-Cherem, J, Palomo-Piñón S, Flores-Padilla G, Romero E, Chong-Martínez BA, Nellen-Hummel H, et al. La valoración preoperatoria en el adulto. Gac Med Mex. 2007:131:267-276.

2. Diaz-Fuentes G, Talib-Hashmi HR, Venkatram S. Perioperative evaluation of patients with pulmonary conditions undergoing non-cardiothoracic surgery. Health Serv Insights. 2016:9:9-23.

3. Canet J, Gallart L, Gomar C, Paluzie G, Vallès J, Castillo J, et al. Prediction of postoperative pulmonary complications in a population-based surgical cohort. Anesthesiology. 2010;113:1338-1350.

4. Gupta H, Gupta PK, Schuller D, Fang X, Miller WJ, Modrykamien A, et al. Development and validation of a risk calculator for predicting postoperative pneumonia. Mayo Clin Proc. 2013;88:1241-1249.

5. Bock M, Fritsch G, Hepner DL. Preoperative laboratory testing. Anesthesiol Clin. 2016;34:43-58.

6. Reilly DF, McNeely MJ, Doerner D, Greenberg DL, Staiger TO, Geist MJ, et al. Self-reported exercise tolerance and the risk of serious perioperative complications. Arch Intern Med. 1999;159:2185-2192.

7. Fleisher LA, Fleischmann KE, Auerbach AD, Barnason SA, Beckman JA, Bozkurt B, et al. 2014 ACC/AHA guideline on perioperative cardiovascular evaluation and management of patients undergoing noncardiac surgery: a report of the American College of Cardiology/American Heart Association Task Force on Practice Guidelines. Circulation. 2014; 9:2215-2245.

8. Rubinsky AD, Sun $H$, Blough DK, Maynard C, Bryson $C L$, Harris $A H$, et al. AUDIT-C alcohol screening results and postoperative inpatient health care use. J Am Coll Surg. 2012;214:296-305.

9. Subedi A, Bhattarai B. Intraoperative alcohol withdrawal syndrome: a coincidence or precipitation? Case Rep Anesthesiol. 2013;2013:761527.

10. Sullivan JT, Sykora K, Schneiderman J, Naranjo CA, Sellers EM. Assessment of alcohol withdrawal: the revised clinical institute withdrawal assessment for alcohol scale (CIWA口Ar). Br J Addict. 1989;84:1353-1357.

11. Alakkad H, Kruisselbrink R, Chin KJ, Niazi AU, Abbas S, Chan VW, et al. Point-of-care ultrasound defines gastric content and changes the anesthetic management of elective surgical patients who have not followed fasting instructions: a prospective case series. Can J Anesth. 2015; 62:1188-1195 
12. Nolan MB, Martin DP, Thompson R, Schroeder DR, Hanson AC Warner DO. Association between smoking status, preoperative exhaled carbon monoxide levels, and postoperative surgical site infection in patients undergoing elective surgery. JAMA Surg. 2017;152:476-483.

13. Wong J, Lam DP, Abrishami A, Chan MT, Chung F. Short-term preoperative smoking cessation and postoperative complications: a systematic review and meta-analysis. Can J Anesth.2012;59:268-279.

14. Nolan MB, Warner DO. Safety and efficacy of nicotine replacement therapy in the perioperative period: a narrative review. Mayo Clin Proc. 2015;90:1553-1561.

15. Gupta H, Gupta PK, Fang X, Miller WJ, Cemaj S, Forse RA, et al. Development and validation of a risk calculator predicting postoperative respiratory failure. Chest. 2011;140:1207-1215.

16. Corso RM, Petrini F, Buccioli M, Nanni O, Carretta E, Trolio A, et al Clinical utility of preoperative screening with STOP-Bang questionnaire in elective surgery. Minerva Anestesiol. 2014;80:877-884.

17. Moore JA, Conway DH, Thomas N, Cummings D, Atkinson D. Impact of a peri-operative quality improvement programme on postoperative pulmonary complications. Anaesthesia 2017:72:317-327.

18. Cassidy MR, Rosenkranz P, McCabe K, Rosen JE, McAneny D. I CO GH: reducing postoperative pulmonary complications with a multidisciplinary patient care program. JAMA Surg. 2013:148:740-745.

19. Chung F, Abdullah HR, Liao P. STOP-Bang Questionnaire: a practical approach to screen for obstructive sleep apnea. Chest. 2016; 149:631-638

20. Stierer TL, Collop NA. Perioperative assessment and management for sleep apnea in the ambulatory surgical patient. Chest. 2015;148:559-565.

21. Raveendran R, Chung F. Perioperative consideration of obstructive sleep apnea in ambulatory surgery. Anesthesiol Clin. 2014;32:321-328.

22. Owens WD. American Society of Anesthesiologists Physical Status Classification System is not a risk classification system. Anesthesiology. 2001;94:378

23. Goldman L, Caldera DL, Nussbaum SR, Southwick FS, Krogstad D, Murray B, et al. Multifactorial index of cardiac risk in noncardiac surgical procedures. N Engl J Med. 1977;297:845-850.

24. Detsky AS, Abrams HB, Forbath N, Scott JG, Hilliard JR. Cardiac assessment for patients undergoing noncardiac surgery. A multifactorial clinical risk index. Arch Intern Med. 1986;146:2131-2134

25. Lee TH, Marcantonio ER, Mangione CM, Thomas EJ, Polanczyk CA Cook EF, et al. Derivation and prospective validation of a simple index for prediction of cardiac risk of major noncardiac surgery. Circulation. 1999:100:1043-1049.

26. Gupta PK, Gupta H, Sundaram A, Kaushik M, Fang X, Miller WJ, et al. Development and validation of a risk calculator for prediction of cardiac risk after surgery. Circulation. 2011;124:381-387.

27. Ridley S. Cardiac scoring systems: what is their value? Anaesthesia. 2003:58:985-991

28. Halabe-Cherem J, Malagón J, Wacher-Rodarte N, Nellen-Hummel H Talavera-Piña, J. La utilidad de la escala de ASA y de la radiografía de tórax como indicadores de riesgo cardiovascular perioperatorio. Gac Med Mex. 1998;134:27-31.

29. Kristensen SD, Knuuti J, Saraste A, Anker S, Bøtker HE, Hert SD, et al 2014 ESC/ESA Guidelines on non-cardiac surgery: cardiovascular assessment and management: the Joint Task Force on non-cardiac surgery: cardiovascular assessment and management of the European Society of Cardiology (ESC) and the European Society of Anaesthesiology (ESA). Eur Heart J. 2014;35:2383-2431.

30. Craig CM, Basman C, Wang ES, Shoffeitt M, Mackenzie CR. Perioperative risk models: a narrative review. J Clin Anesth Manag. 2016;1:1-11

31. Glance LG, Lustik SJ, Hannan EL, Osler TM, Mukamel DB, Qian F, et al. The Surgical Mortality Probability Model: derivation and validation of a simple risk prediction rule for noncardiac surgery. Ann Surg. 2012;255:696-702.

32. Jeger RV, Probst C, Arsenic R, Lippuner T, Pfisterer ME, Seeberger MD, et al. Long-term prognostic value of the preoperative 12-lead electrocardiogram before major noncardiac surgery in coronary artery disease. Am Heart J. 2006;151:508-513.

33. Patel MR, Bailey SR, Bonow RO, Chambers CE, Chan PS, Dehmer GJ, et al. ACCF/SCAI/AATS/AHA/ASE/ASNC/HFSA/HRS/SCCM/SCCT/ SCMR 2012 appropriate use criteria for diagnostic catheterization: a report of the American College of Cardiology Foundation Appropriate Use Criteria Task Force, Society for Cardiovascular Angiography andlnterventions, American Association for Thoracic Surgery, American Heart Association, American Society of Echocardiography, American Society of Nuclear Cardiology, Heart Failure Society of America, Heart Rhythm Society, Society of Critical Care Medicine, Society of Cardiovascular Computed Tomography, Society for Cardiovascular Magnetic Resonance, and Society of Thoracic Surgeons. J Am Coll Cardiol. 2012;29:1995-2027.

34. Caprini JA. Mechanical methods for thrombosis prophylaxis. Clin Appl Thromb Hermost. 2010;16:668-673.
35. Ho KM, Tan JA. Stratified meta-analysis of intermittent pneumatic compression of the lower limbs to prevent venous thromboembolism in hospitalized patients. Circulation. 2013;128:1003-1020.

36. Chan KE, Thadhani RI, Maddux FW. No difference in bleeding risk between subcutaneous enoxaparin and heparin for thromboprophylaxis in end-stage renal disease. Kidney Int. 2013;84:555-561.

37. Baron TH, Kamath PS, McBane RD. Management of antithrombotic therapy in patients undergoing invasive procedures. $\mathrm{N}$ Engl $\mathrm{J}$ Med. 2013;368:113-124.

38. Venker BT, Ganti BR, Lin H, Lee ED, Nunley RM, Gage BF. Safety and efficacy of new anticoagulants for the prevention of venous thromboembolism after hip and knee arthroplasty: a meta-analysis. J Arthroplasty. 2017;32:645-652.

39. Kaplan EB, Sheiner LB, Boeckmann AJ, Roizen MF, Beal SL, Cohen SN, et al. The usefulness of preoperative laboratory screening. JAMA 1985;253:3576-3581.

40. Smetana GW, Macpherson DS. The case against routine preoperative laboratory testing. Med Clin North Am. 2003:87:7-40.

41. Srivastava $U$, Kumar $A$. Role of routine laboratory investigations in preoperative evaluation. J Anaesthesiol Clin Pharmacol. 2011;27:174-179.

42. Alsumait BM, Alhumood SA, Ivanova T, Mores M, Edeia M. A prospective evaluation of preoperative screening laboratory tests in general surgery patients. Med Princ Pract. 2002;11:42-45.

43. Blessberger $\mathrm{H}$, Kammler J, Domanovits $\mathrm{H}$, Schlager $\mathrm{O}$, Wildner $\mathrm{B}$, Azar D, et al. Perioperative beta-blockers for preventing surgery related mortality and morbidity. Cochrane Database Syst Rev. 2014;18:CD004476.

44. Devereaux PJ, Sessler DI. Cardiac complications in patients undergoing major noncardiac surgery. N Engl J Med. 2015;373:2258-2269.

45. Stern T, Cifu AS. Perioperative ם-blocker therapy. JAMA. 2015; 313:2486-2487.

46. Hollmann C, Fernandes NL, Biccard BM. A systematic review of outcomes associated with withholding or continuing angiotensin-converting enzyme inhibitors and angiotensin receptor blockers before noncardiac surgery. Anesth Analg. 2018;127:678-687.

47. Arnold MJ, Beer J. Preoperative evaluation: a time-saving algorithm. J Fam Pract. 2016;65:702-710.

48. Sudhakaran S, Surani SR. Guidelines for perioperative management of the diabetic patient. Surg Res Pract. 2015;2015:284063.

49. Sebranek JJ, Lugli AK, Coursin DB. Glycaemic control in the perioperative period. Br J Anaesth. 2013:111:18-34.

50. Kelly KN, Domajnko B. Perioperative stress-dose steroids. Clin Colon Rectal Surg. 2013;26:163-167

51. Liu MM, Reidy AB, Saatee S, Collard CD. Perioperative steroid management: approaches based on current evidence. Anesthesiology. 2017;127:166-172.

52. Douketis JD, Spyropoulos AC, Spencer FA, Mayr M, Jaffer AK, Eckman $\mathrm{MH}$, et al. Perioperative management of antithrombotic therapy: antithrombotic therapy and prevention of thrombosis, $9^{\text {th }}$ ed: American College of Chest Physicians Evidence-Based Clinical Practice Guidelines. Chest. 2012;141:e326S-e350S.

53. Mikhail MA, Mohabbat AB, Ghosh AK. Perioperative cardiovascular medication management in noncardiac surgery: common questions. Am Fa. Physician. 2017;95:645-650.

54. Douketis JD, Spyropoulos AC, Kaatz S, Becker RC, Caprini JA, Dunn AS, et al. Perioperative bridging anticoagulation in patients with atrial fibrillation. N Engl J Med. 2015:373:823-833.

55. Berríos-Torres SI, Umscheid CA, Bratzler DW, Leas B, Stone EC, Kelz RR, et al. Centers for Disease control and prevention guideline for the prevention of surgical site infection. JAMA Surg. 2017:152:784-791.

56. Bratzler DW, Dellinger EP, Olsen KM, Perl TM, Auwaerter PG, Bolon MK, et al. Clinical practice guidelines for antimicrobial prophylaxis in surgery. Am J Health Syst Pharm. 2013;70:195-283.

57. Halm EA, Browner WS, Tubau JF, Tateo IM, Mangano DT. Echocardiography for assessing cardiac risk in patients having noncardiac surgery. Study of Perioperative Ischemia Research Group. Ann Intern Med. 1996;125:433-441.

58. Rohde LE, Polanczyk CA, Goldman L, Cook EF, Lee RT, Lee TH. Usefulness of transthoracic echocardiography as a tool for risk stratification of patients undergoing major noncardiac surgery. Am J Cardiol. 2001:87:505-509.

59. Schwitter J, Wacker CM, Wilke N, Al-Saadi N, Sauer E, Huettle K, et al. MR-IMPACT II: Magnetic Resonance Imaging for Myocardial Perfusion Assessment in Coronary artery disease Trial: perfusion-cardiac magnetic resonance vs. single-photon emission computed tomography for the detection of coronary artery disease: a comparative multicentre, multivendor trial. Eur Heart J. 2013;34:775-781.

60. Das MK, Pellikka PA, Mahoney DW, Roger VL, Oh JK, McCully RB, et al. Assessment of cardiac risk before nonvascular surgery: dobutamine stress echocardiography in 530 patients. J Am Coll Cardiol. 2000;35:1647-1653. 